\title{
C-Terminal Fibroblast Growth Factor 23 Measurement
}

National Cancer Institute

\section{Source}

National Cancer Institute. C-Terminal Fibroblast Growth Factor 23 Measurement. NCI

Thesaurus. Code C135419.

The determination of the amount of the C-terminal fibroblast growth factor 23 in a biological sample. 